\title{
A fibrin sealant for perforated and preperforated corneal ulcers
}

\author{
FRANÇOISE M LAGOUTTE, LAURENT GAUTHIER, \\ AND PASCAL R M COMTE \\ From the Department of Ophthalmology, Hôpital des Enfants, Bordeaux, France
}

SUMMARY Fibrin sealant is used to close perforated or preperforated corneal ulcers. In addition to the usual advantages of cyanoacrylates it is degraded physiologically and provides a good support for corneal healing. Corneal grafting can be avoided when contraindicated or postponed when conditions allow. This technique has been successful in nine eyes of eight patients.

Perforated corneal ulcers are difficult to treat, whatever their cause. The most commonly used treatment is emergency penetrating keratoplasty, but the poor visual prognosis for these emergency grafts requires other therapeutic solutions. The highly hydrophilic therapeutic lens can be used only for perforations of very small diameter.

The deposit of a layer of fibrin on the surface of the ulcer causes the anterior chamber to be closed immediately, with the hope that the cornea will subsequently heal. This avoids the need for grafts, which may fail if performed under unfavourable conditions, such as sicca syndrome or pemphigoid disease.

\section{Materials and methods}

The tissue adhesive used is Tisseel (Immuno France). Its action is the result of the interaction of two solutions. The first is an adhesive solution containing: (1) human fibrinogen freeze-dried at 30 times plasma concentration ( $90 \%$ proteins); (2) factor XIII, a fibrin-stabilising factor extracted from human plasma at 10 times plasma concentration $(10 \mathrm{U} / \mathrm{ml})$; (3) fibronectin (5\% proteins); (4) low concentration plasminogen $(0 \cdot 13 \mathrm{~g} / \mathrm{l})$; (5) albumin ( $3 \%$ proteins); (6) aprotinin, a protease inhibitor of bovine origin at a concentration of $3000 \mathrm{UK}$. The second is a catalyst formed from a mixture of two solutions: (1) freezedried thrombin at two different concentrations, namely, $500 \mathrm{U}-\mathrm{NIH} / \mathrm{ml}$ for rapid setting in 30 seconds,

Correspondence to Françoise $M$ Lagoutte, MD, Hőpital des Enfants, 168 Cours de l'Argonne, 33077 Bordeaux Cedex, France. and $4 \mathrm{U}-\mathrm{NIH} / \mathrm{ml}$ for slow setting in 3 minutes; (2) calcium chloride at a concentration of $40 \mathrm{mmol} / \mathrm{l}$.

A surgical microscope and a local anaesthesia with oxybuprocaine drops are used, and the eye is opened with a blepharostat. The abrasion of necrotic tissue is performed with cellulose sponges.

Thombin is used at a $500-\mathrm{U}-\mathrm{NIH} / \mathrm{ml}$ concentration to ensure rapid setting. The two previously prepared solutions are applied either simultaneously via a single mixing needle (a technique possible thanks to the Duplojet device delivered with the kit) or successively, when the fibrin solution should be applied first, as it is more viscous and less likely to run. We ourselves prefer simultaneous application, as it provides both more homogeneous polymerisation and the optimal concentration ratio for the different compounds.

After two minutes' setting the tissue adhesive will have extended considerably beyond the edges of the ulcer and the excess must be cut to a smooth bevel. This is an easy task, as the tissue adhesive has very little adherence to the epithelium of the healthy cornea, where there is no collagen, the substance with which fibrin crosslinks.

A soft lens is applied in order to limit any shearing forces due to palpebral movements which could remove the sealant plug.

A flat anterior chamber can be deepened by a viscous substance such as sodium hyaluronate prior to the use of the tissue adhesive if the anterior chamber is still watertight enough to retain the viscous substance, or subsequently if not. In the latter case any iridocorneal synechiae should be reduced via the limbic injection punctum. 
Postoperative treatment consists of four daily instillations of antibiotic drops. The durability of the tissue adhesive is considerably increased by six daily instillations of aprotinin (Iniprol), as in cases 6, 7, 8, and 9.

\section{Results}

Presented chronologically, these demonstrate the successful evolution of the technique.

CASE 1

A 61-year-old female, with severe pemphigoid disease. The right eye was already lost owing to a corneal perforation with unsuccessful keratoprosthesis. In the left eye there was ulcerative vascularised keratitis. During an attack of increased inflammatory cornea this developed a perforated ulcer and overall thinning. After application of fibrin sealant the ulcer closed over and remained so for 18 months, thus leaving a corneal leucoma and enabling the patient to maintain her poor vision as before.

CASE 2

A 74-year-old woman with inferior paracentral perforated ulcer in a very serious keratoconjunctivitis sicca. The patient presented with a totally collapsed anterior chamber, which was reformed within 48 hours by means of a bandage contact lens; the ulcer opened again afterwards. Fibrin sealant was then applied together with reformation of the anterior chamber with sodium hyaluronate introduced by a limbic puncture. The sealant plug was lysed within 48 hours, but the ulcer was definitively blocked off. Ten months later, there was still a corneal leucoma at the site of the perforation, the anterior chamber was quiet with no iridocorneal synechiae, and visual acuity was $20 / 80$. No keratoplasty was programmed because of the sicca syndrome.

CASE 3

A woman aged 61 who had a graft in 1982 for an herpetic corneal necrosis. A further necrotic ulceration of the graft occurred in December 1985. She was admitted to hospital on 27 December 1985 for perforation of the ulcer. No emergency transplant was available, so the ulcer was filled with Tisseel and the anterior chamber was deepened. Here again the Tisseel was covered with a bandage contact lens. Her condition remained stable for three days, after which the ulcer opened again. However, it was then possible to make a transplant. In this case though the sealant did not ensure sufficient closure to avoid a transplant, it made it possible to wait for a graft under satisfactory conditions (closure of the fistula, reformation of the anterior chamber).
CASE 4

This man aged 66 had had a right torpid corneal ulcer of traumatic origin six months previously. He was admitted to hospital initially for keratoplasty. Examination revealed an unperforated descemetocele and a satisfactorily quiet anterior chamber. Tissue adhesive was applied together with a bandage contact lens. Twelve days later the sealant was still in place and the ulcer had healed; a transplant was performed four months later. After two years the visual acuity was $20 / 30$.

\section{CASE 5}

A man 81 years old with chronic paracentral inferior ulcer of the left eye of unknown origin. The ulcer was developing into a descemetocele. A layer of fibrin sealant was applied, together with a bandage contact lens. The ulcer healed with a visual acuity of 20/30, but the patient was lost to follow-up. He returned four months later with bilateral purulent conjunctivitis and left corneal necrosis too severe for any treatment by this method. In fact the origin of the ulcer proved to be a chronic dacryocystitis.

\section{CASE 6}

A 51-year-old woman with Sjögren's syndrome, who had received no ophthalmic care. She had perfectly symmetrical perforations of both corneas, and stated she had had them for three weeks. Both perforations were round, with a punch diameter of $2.5 \mathrm{~mm}$, paracentral and temporal, with an iris plug in the ulcer, positive Seidel's test, and a collapsed anterior chamber (Fig. 1). The fibrin sealant was applied at the site of perforation, and the anterior chamber was deepened by limbic puncture after sealing, since the viscous substance would not have remained in the anterior chamber. Seventy-two hours later the sealant plugs had completely dissolved, making it necessary

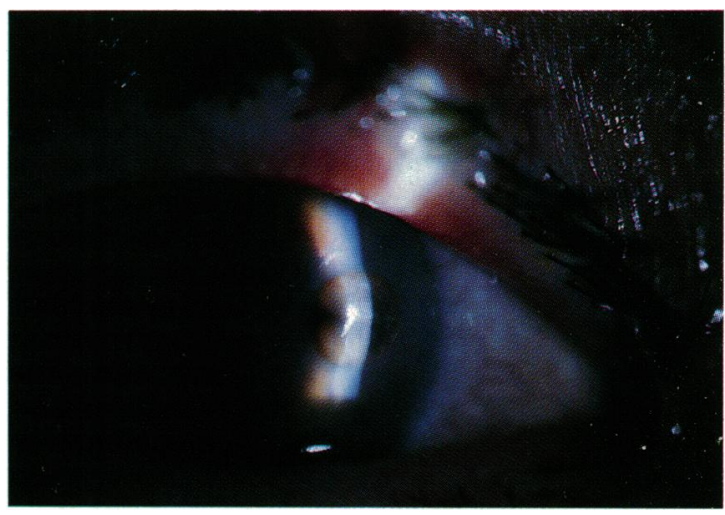

Fig. 1 Case 6, left eye, perforated ulcer with positive Seidel's test and iris plug prior to treatment. 


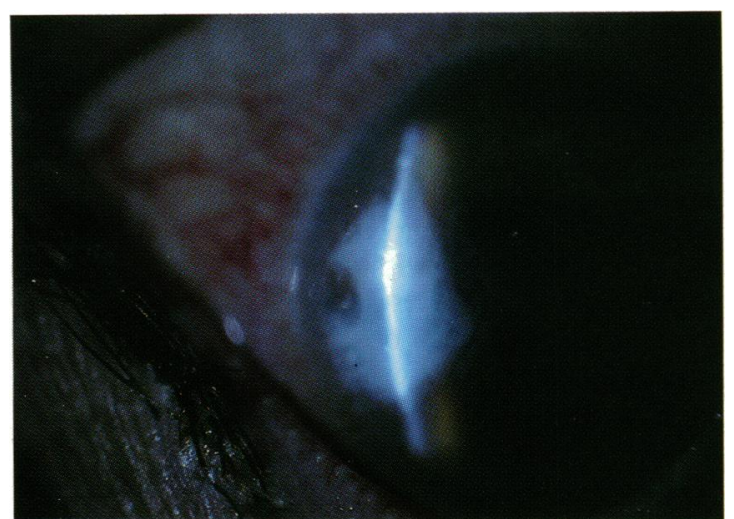

Fig. 2 Case 6, with sealant plug and bandage lens three days after treatment.

to reapply the sealant. A bandage lens was applied. To avoid rapid fibrinolysis, aprotinin was instilled six times a day. The sealant remained one month (Fig. 2), leaving a bilateral corneal leucoma. The anterior chamber was quiet. In both eyes there was a very slight filiform iridocorneal synechia at the perforation site; this would have been insufficient to close a perforation of that size. Two months later the corrected visual acuity was 20/30 right eye, 20/25 left eye, with an ocular pressure of $10 \mathrm{mmHg}$ in both eyes; the scar was stable and no graft was advised (Fig. 3).

Four months later the visual acuity was 20/60 right eye, 20/25 left eye. New stromal inflammation had appeared in previously healthy areas but was stopped with the usual medication.

CASE 7

A 66-year-old man, suffering from a rosacea presented with an ulcer of the right eye which had perforated 7 days previously. This perforation, which was a clear $2 \mathrm{~mm}$ hole, temporal paracentral, was

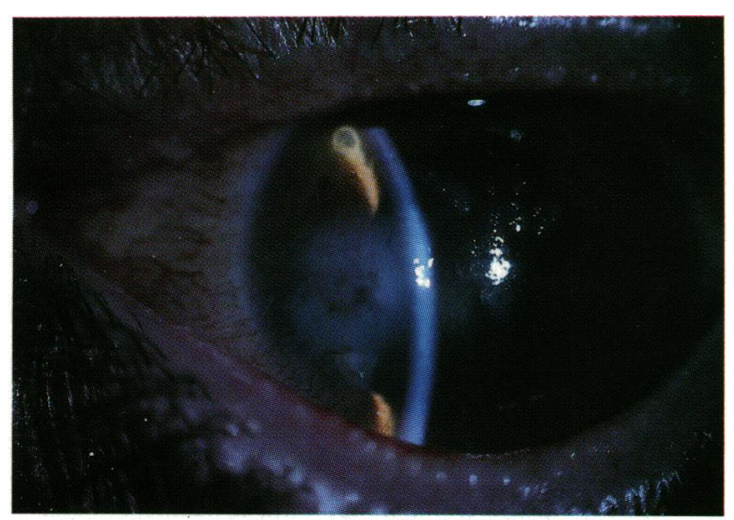

Fig. 3 Case 6, two months later with stable scar and $20 / 15$ acuity. blocked by an iris plug. Fibrin sealant was placed in the perforation and the anterior chamber was reformed with sodium hyaluronate introduced by limbic puncture. A bandage lens was applied and Iniprol was instilled 6 times a day. Complete healing ensued after one month. The visual acuity was $20 / 60$ and a graft was not advised.

\section{CASE 8}

A $131 / 2$-year-old child was suffering from corneal anaesthesia and facial paresis owing to a lesion of the posterior fossa. An ulcer, which had started a month earlier, had perforated. The lens was blocking the perforation. Fibrin sealant was applied, and the anterior chamber was reformed with sodium hyaluronate. A partial tarsorrhaphy was also performed, and Iniprol was instilled six times a day. After two months the ulcer seemed to be definitely healed.

\section{Discussion}

The idea of using surgical glue in the treatment of perforated or preperforated ulcers is not new. As early as the 1960 s surgical sealants and their various applications were proposed. ${ }^{12}$ A study of cyanoacrylates revealed that their properties depend on the chemical variety used. These sealants are known to have anti-infectious properties inversely proportional to the length of their constituent monomers ${ }^{3}$ and an inhibiting effect on corneal necrosis. ${ }^{4}$ Their ocular toxicity, however, is variously assessed. Some workers consider cyanoacrylates are responsible for corneal inflammation, neovascularisation of the stroma, and inflammatory reactions in the anterior chamber ${ }^{56}$ while others consider that they are well tolerated. ${ }^{78}$

In fact, tolerance to cyanoacrylate varies according to the quantity of glue. When very little is used, the inflammatory reaction and vascularisation are minimal, but when the glued area covers as much as a quarter of the cornea the result is poor. ${ }^{9}$

For a long time the requirement not to introduce this glue into the anterior chamber meant that cyanoacrylates were used for small diameter $(1 \mathrm{~mm})$ perforations. (An air bubble placed inside the anterior chamber stopped any glue from entering.) Hirst and De Juan ${ }^{10}$ were the first to combine the use of sodium hyaluronate and cyanoacrylates to treat perforations up to $3 \mathrm{~mm}$. The use of a free tissue patch associated with cyanoacrylate made it possible to limit this penetration even more. ${ }^{11}$

Perforations and descemetoceles treated with tissue adhesive have a better prognosis, as shown by Hirst and associates, ${ }^{12}$ who report an improvement in visual acuity in eyes treated with this technique and a clear decrease in the enucleation rate $(6 \%)$. This has 
been confirmed by Weiss et al. ${ }^{13}$ Similarly Foster and Duncan $^{14}$ have obtained a much better prognosis for grafts performed after cyanoacrylates have been used (85\% clear grafts) than those practised 'à chaud' (no clear grafts).

Such perforations can also be treated by lamellar graft. The corneal lamella may come from a fresh donor eye; in this case the quality of the donor cornea is not important. A lamella graft may also be sealed by fibrin sealant, and Flacinelli et al..$^{15}$ report on four patients, two of whom recovered visual acuity of $80 /$ 60 and $20 / 100$. With this procedure a third patient was able to wait for a perforating graft.

More recently a planolyophilised epikeratopatch stitched to the surface of the perforated cornea has been proposed for the same purpose (McDonald M B, Kaufman H E, Koenig S B, personal communication). This technique has the advantage of being available for treating perforations of more than $2 \mathrm{~mm}$ diameter but is very expensive and perishable.

The use of a fibrin sealant has many advantages. It is justified by the high collagen content of the corneal stroma denuded by the ulceration. Duckert et al. ${ }^{16}$ and Mosher ${ }^{17}$ have demonstrated the crosslinking of fibrin and fibronectin with collagen. This crosslinking explains the high adherence of this sealant to collagen-rich tissue. It stimulates healing owing to the presence of factor XIII in the fibrin sealant; these substances are known to stimulate the proliferation of fibroblasts. ${ }^{18}$ It has some anti-infectious activity: Stanek et al. ${ }^{19}$ have shown that a strain of Staphylococcus aureus grows less in a fibrin clot than in a blood clot. It has no corneal toxicity ${ }^{21}$ and no toxicity for the lens. On the contrary, Buschmann et al. ${ }^{21}$ have shown that fibrin can be used to stop a perforation of the anterior capsule of the lens in order to avoid opacification.

A fibrin sealant has already been used experimentally in the rabbit to repair retinal tears. ${ }^{22}$ Pathological examination revealed perfect tolerance and in particular no tendency to promote vitreoretinal proliferation.

The use of a substance of human origin raises the problem of virus transmission, particularly hepatitis $B$ and HIV. In order to avoid such transmission the plasmas used are subjected to radioimmunoassay (Hbs), and enzyme linked immunosorbent assay (ELISA) for anti HIV antibodies, in accordance with the criteria accepted by the F.D.A. The same tests are repeated on the plasma pools formed after fractionation and on the Tisseel itself. After freezedrying the finished product also undergoes thermoviroinactivation for 30 hours at $60^{\circ} \mathrm{C}$. This method has been used experimentally to inactivate high concentrations of three model viruses (Sinobis virus, vesicular stomatitis virus, and HTLV III.
It has also been proved that the use of fibrin seal does not increase the risk of non-A non-B hepatitis. ${ }^{23}$

In our experience, this simple technique has made it possible to avoid keratoplasty in nine patients, for four of whom a severe sicca syndrome meant a very poor prognosis for any graft, even after the perforation had completely healed. We have never encountered any problems with infection of the treated ulcer, nor has any residual inflammation of the anterior chamber been observed after resorption of the inflammatory reaction due to the perforation.

The technique is simple, non-invasive, and fully reversible. It has the major advantage over synthetic sealants of providing a true support and helping the cornea to heal. The clot of fibrin applied degrades very gradually and is replaced by fibrosis, of which it forms the initial web. In the event of failure it in no way hinders keratoplasty and can even improve the prognosis. When successful the perforation is replaced by a corneal scar which, if not on the visual axis, or if a graft is contraindicated, enables keratoplasty to be definitely avoided.

The use of this organic sealant has in addition to the usual advantages of surgical sealants those of being well tolerated, degraded by the physiological and non-inflammatory mechanism of fibrinolysis, and of providing a good support for corneal healing.

\section{References}

1 Straatsma BR, Allen RA, Hale PN, Gomez R. Experimental studies employing adhesive compounds in ophthalmic surgery. Ophthalmology 1963: 67: 320-33.

2 Bloomfield BR, Barnet AH, Kanter PD. The use of Eastman 910 monomer as an adhesive in ocular surgery. Am J Ophthalmol 1963: 55: 742-8.

3 Lehman RAW, West RL, Leonard F. Toxicity of alkyl-2cyanoacrylates. II. Bacterial growth. Arch Surg 1966; 93: 447-50.

4 Fogle JA, Kenyon KR, Foster CS. Tissue adhesive arrests stromal melting in human cornea. Am J Ophthalmol 1980; 89: $795-802$.

5 Aronson SB, McMaster PBR, Moore TE, Coon MA. Toxicity of the cyanoacrylates. Arch Ophthalmol 1970; 84: 342-9.

6 Girard LG, Cobb S, Reed T, William B, Minaya J. Surgical adhesives and bonded contact lens: an experimental study. Ann Ophthalmol 1969; 1: 65-74.

7 Refojo MF. Surgical adhesives in ophthalmology. J Macromol Sci 1970; A4(3): 667-74.

8 Sani BP, Refojo MF. ${ }^{4} \mathrm{C}$-isobutyl 2-cyanoacrylate adhesive. Determination of absorption in the cornea. Arch Ophthalmol 1972; 87: 216-21.

9 Refojo MF, Dohlman CH, Ahmad B, Carroll JM, Allen JC. Evaluation of adhesives for corneal surgery. Arch Ophthalmol 1968: 80: 645-56.

10 Hirst LW, De Juan JR. Sodium hyaluronate, tissue adhesive in treating corneal perforations. Ophthalmology 1982; 89: 1250-3.

11 Hyndiuk RA, Hull DS, Kinyoun JL. Free tissue patch and cyanoacrylate in corneal perforations. Ophthalmic Surg 1974; 5: $50-5$.

12 Hirst LW, Smiddy WE, Stark WJ. Corneal perforations: changing methods of treatment, 1960-1980. Ophthalmology 1982: 89: 630-4. 
13 Weiss JL, Williams P, Lindstrom RL, Doughman DJ. The use of tissue adhesive in corneal perforations. Ophthalmology 1983; 90: $610-5$.

14 Foster CS, Duncan J. Penetrating keratoplasty for herpes simplex keratitis. Am J Ophthalmol 1981; 92: 336-43.

15 Flacinelli G, Colliardo P. Petitti V, Pinna C. Tissucol (Tisseel) in surgery of the ocular anterior segment. In: Schlag G, Redl H, eds. Fibrin sealant in operative medicine. Ophthalmology neurosurgery. Berlin, Heidelberg: Springer, 1986: 2: 98-103.

16 Duckert F, Nyman D, Gatspar H. Factor XIII, fibrin and collagen. Collagen-platelet interaction. Stuttgart, New York: F K Schattauer, 1978: 391-6.

17 Mosher DF. Crosslinking of cold insoluble globulin by fibrinstabilizing factor. J Biol Chem 1975; 250: 6614-21.

18 Bruhn HD, Christopers E, Pohl J, Scholl G. Regulation der fibroblasten prolifierung durch Fibrinogen Fibrin. Fibronectin und Factor XIII. In: Schimpf $\mathrm{K}$, ed. Fibrinogen, Fibrin und Fibrinkleber. Stuttgart: Schattauer, 1980: 217-26.
19 Stanek G, Bosch P, Weber P. Verglerchende quantitätive untersuchung des wachstums von Staphylococcus aureus im Fibrin-Klebesystem und im Blutkoagulum. Zentralbl Bakteriol Mikrobiol Hyg (A) 1978; 240: 441-6.

20 Holtmann HW. Stein HJ. Experimentelle untersuchungen zur Hornhautwundverklebung mittels hochkonzentrierten Fibrinogen. Ber Zusammenkunft Dtsch Ophthalmol Ges 1977: 220-5.

21 Buschmann W, Waller W, Gehrig O, Vogt E. Experimental studies on the treatment of lens capsule perforations. Ophthalmic Res 1980; 12: 146-51.

22 Nasaduke I, Waller W, Gehrig O, Vogt E. Intraocular effect of rabbit fibrin sealant used in experimental retinal holes and detachments. Ann Ophthalmol in press.

23 Scheele J, Schricker L. Hepatitisrisiko der Fibrinklebung in der Allgemeinchirurgie. Med Welt 1981; 32: 783-8.

Accepted for publication 7 December 1988. 